\title{
AN EMPIRICAL ANALYSIS CONCERNING THE KNOWLEDGE SHARING ACTIVITIES
}

\author{
Ali E. AKGÜN \\ Halit KESKİN \\ Ayşe GÜNSEL \\ Gebze Institute of Technology, Turkey
}

\begin{abstract}
In this study knowledge is considered as explicit and tacit; and in line with this, knowledge sharing mechanisms are classified into two categories: explicit knowledge sharing and tacit knowledge sharing; and the relationships between trust, organizational culture and knowledge sharing mechanisms are investigated. According to the regression analyses, trust and flexible culture have positive effects on explicit and tacit knowledge sharing mechanisms; and the impact (magnitude) of trust on tacit knowledge sharing is higher than the flexible culture; while the affect of flexible culture on explicit knowledge sharing is higher than trust
\end{abstract}

\section{INTRODUCTION}

Today's complex, competitive and dynamic business environment dictates knowledge sharing of vital importance for organizations., enabling them to develop skills and competences, increase their value, and sustain their survival (Du et al., 2007; Matzler et al., 2005). A significant amount of research has suggested that knowledge sharing is a requirement for developing new technologies and products and eventually for the survival of the organization in the globalized and harsh competition (e.g., Nonaka and Takeuchi, 1995).

To give full particulars of the multidimensional nature of knowledge first we must consider the knowledge concept which is a composite of capacity of the individual, attitudes and information (Bhatt, 2001:70). This definition implies that knowledge is a subjective phenomenon which comes into being within the context of human mind (Beijerse, 2000:164). Hence the sharing of this subjective phenomenon is affected by many factors such as trust which shows the eagerness of an individual for sharing his/her knowledge with the others (Panteli and Sockalingam, 2005) or organizational culture that shapes the behaviors of the members of the organization (Keskin et al., 2006). Accordingly in this study it is aimed to investigate the knowledge sharing activities from both theoretical and empirical perspectives. According to the articulation level, knowledge is classified into two types as explicit and tacit; so knowledge sharing activities will be handled as explicit knowledge sharing and tacit knowledge sharing. And the effects of trust and organizational culture on knowledge sharing will be empirically analyzed.

\section{BACKGROUND}

\section{Knowledge and Knowledge Sharing}

Knowledge is a firm's most important resource for the reason that it embodies intangible assets, routines, and creative processes that are hard to copy (eg. Renzl, 2006; Panteli and Sockalingam, 2005). Smith et al. stated that the ability of an organization's members to combine, transfer and share knowledge determines the success of new product development process. Furthermore, as Argote et al. (2000) highlight the ability to share knowledge among the departments and hierarchical levels contributes considerably to the firm performance. Performance can be enhanced, when people share information, best practices, lessons learned, experiences, insights. Individuals share knowledge via more or less intense interaction. To a greater extent firms are utilizing interdisciplinary organizational structures in which employees share knowledge and expertise within and between units, groups and hierarchical levels with the intention of dealing with complex tasks (Krogh, 2002).

There are many studies concerning the properties of knowledge related to articulation (see e.g., Nonaka and Takeuchi, 1995) and their effect on knowledge sharing. Zander and Kogut (1995, Renzl, 2006) see state that knowledge that can be articulated and codified can be documented, transferred and communicated more easily than non-codifiable knowledge. According to the articulability, knowledge 
is classified into two types as tacit and explicit by Polanyi (1966 s.135-146).

Explicit knowledge: is the type of knowledge, which is much easier to articulate, capture, codify, document, shape and imitate (Bhatt, 2001:70). Explicit knowledge is closer to information -the system-bound side of knowledge- (Beijerse, 2000:164). It is transmittable through formal, systematic language and information technologies and may adopt the form of computer programs, patents, diagrams (Perez and Pablos, 2003:83).

Tacit knowledge: is the knowledge type which is hard to document, transfer, codify, articulate, replicate and imitate. It is embodied in the background of the organization. It takes form in human mind, behavior, perception and mental processes. It is related to the people-bound side of knowledge (Beijerse, 2000:164). Tacit knowledge is contingent on firm's own history and its unique circumstances; it is acquired and transferred by experience (Choi and Lee, 2003: 406; Bhatt, 2001:70).

In the light of this classification, knowledge sharing activities will be handled as explicit knowledge sharing and tacit knowledge sharing

\section{Trust}

As addressed by Argote et al. and Szulanski, knowledge sharing is a rather difficult challenge in practice. Considering the multidimensional character of knowledge there are many factors affecting the knowledge sharing process. What makes individuals share knowledge efficiently with others in organizations is a main question (e.g., Chowdhury, 2005; Wasko and. Faraj, 2005 and Mooradian et al., 2007). Trust is regarded as an important factor behind individuals' decision to share knowledge. Prior studies illustrated that trust affects workplace attitudes, behaviors, and performance (e.g., Jones and George, 1998; Mayer et al., 1995). The notion of trust is problematic with respect to the definition of trust itself, and antecedents and outcomes of trust are often complex. In the light of the existing body of literature regarding the organizational setting, trust is defined as the belief in, and willingness to depend on, another party (e.g., Dirks and Ferin, 1995). In the context of knowledge sharing, a trusting person is more eager to give useful knowledge to others. Trust is assumed as a facilitator of knowledge sharing. In the sociological literature, it is underlined that trust involves not only individuals' beliefs about others, but also their behavior and their eagerness to use knowledge to take a role in future actions (Renzl, 2006).
Predictably, trust has been recognized as being "at the center of knowledge sharing". The facilitator effect of interpersonal trust in general and trust in management in particular on knowledge sharing is obvious (Panteli and Sockalingam, 2005; Renzl, 2006). Several authors have showed that trust is a 'need to have' quality in business interactions and teamwork activities [Dirks and Ferin, 1995, Mayer and Gavin, 2005; Ruppel and Harrington, 2001]. Seeing that trust improves the quality of dialogue and discussions which facilitates the sharing of knowledge; trust is a key to effective communication [Lucas, 2005] Trust is also vital for minimizing risks that arise from exposure to opportunistic behavior by partners, uncertainty, ambiguity and incomplete information, which characterize inter-organizational arrangements. (Panteli and Sockalingam, 2006). Accordingly our first and second hypotheses are offered:

H1: Trust is positively related to explicit knowledge sharing

H2: Trust is positively related to tacit knowledge sharing

\section{Organizational Culture}

Another concept which is assumed to be closely related to knowledge sharing is organizational culture. Culture can be defined as a group of tacit assumptions that is shared by a group of people and that forms their thoughts, feelings, attitudes, and as well as their behaviors (Keskin et al., 2006). As a learnt collective human behavior, culture affects all the parts of the human life as a complex system from which the traditions, manners, beliefs and values are acquired, then shared and adopted. (Chacko, 2003: 1088). Organizational culture is a multifaceted construct that involves many concepts including: values, basic assumptions, stories, rites and ceremonies, and shared meanings. Organizational culture is the key component of organizational change and renewal (Santoro and Gopalakrishnan, 2000).

An effective organizational culture is one of the basic components affecting organizational abilities to survive and succeed in the long term (Yang, 2007). Some organizations are risk-seeking; continuously searching for new knowledge streams whereas other are riskavoiders; preferring stability and the status-quo than the uncertainty and ambiguity of change. Thus culture determines the knowledge sought and acquired along with the knowledge building activities that are tolerated and promoted. (2000) state that, an organizational culture with openness and incentive themes effectively 
facilitates the integration of individual competencies into organizational knowledge base by learning and knowledge creating and sharing (Yang, 2007). Hence, culture plays a role as a knowledge-screening and knowledge-control mechanism. Following the theoretical model of cultural traits of firms with high levels of adaptability and involvement are categorized as having flexible and change-oriented cultures whereas firms with high levels of consistency and sense-ofmission are classified as having stable and directionoriented cultures. Using this framework as our focal point, we relate this combination of cultural traits to the knowledge sharing activities

Accordingly our third, fourth, fifth and sixth hypotheses are offered:

H3: The more flexible and change-oriented an organization's culture the greater the explicit knowledge sharing activities

H4: The more stable and direction-oriented an organization's culture the less the explicit knowledge sharing activities

H5: The more flexible and change-oriented an organization's culture the greater the tacit knowledge sharing activities

H6: The more stable and direction-oriented an organization's culture the less the tacit knowledge sharing activities

\section{METHODOLOGY}

The aim of this study is to evaluate the effects of trust and flexible versus stable cultures on explicit and tacit knowledge sharing. In order to empirically investigate the hypothesis, small and medium sized firms located around Gebze were surveyed. Using the documents obtained from Gebze Chamber of Commerce and Kocaeli Chamber of Industry, 250 firms among 1000 are identified as the target group of the research because of their availableness. Tools such as e-mail, letter and face to face interviews are used for gathering data. One middle manager from each company had received the survey. As total of 101 questionnaires among 250 has returned. The ratio of participation is approximately $40 \%$. All constructs were measured with existing scales. All items were measured on a seven point Likert-type scale where $1=$ strongly disagree and $7=$ strongly agree. Data is evaluated through SPSS 13.0. The relationships between the variables are tested using correlation, reliability, regression and factor analyses. The mean age of the participants were 33.27 (s.d.=5.58); the proportion of women, 9,8\%, and married $69,5 \%$. Of the participants, $\% 81$ had university educations and $\% 17$ had master education. $75,78 \%$ of the participants were from manufacturing industry;
$24,22 \%$ of the participants were from service industry. Trust: Trust was measured using four items from Inkpen (1992) and Mohr and Spekman`s (1994) trust scale

Flexible Culture: To measure flexible culture, this study used Santoro and Gopalakrishnan`s (2000) flexible culture scale that consists of four items. Stable Culture: Stable culture was measured using four items from Santoro and Gopalakrishnan`s (2000) stable culture scale

Explicit knowledge sharing: To measure explicit knowledge sharing, this study used Lee's (2001) explicit knowledge sharing scale that consists of four items.

Tacit knowledge sharing: Tacit knowledge sharing was measured using three items from Lee's (2001) tacit knowledge sharing scale

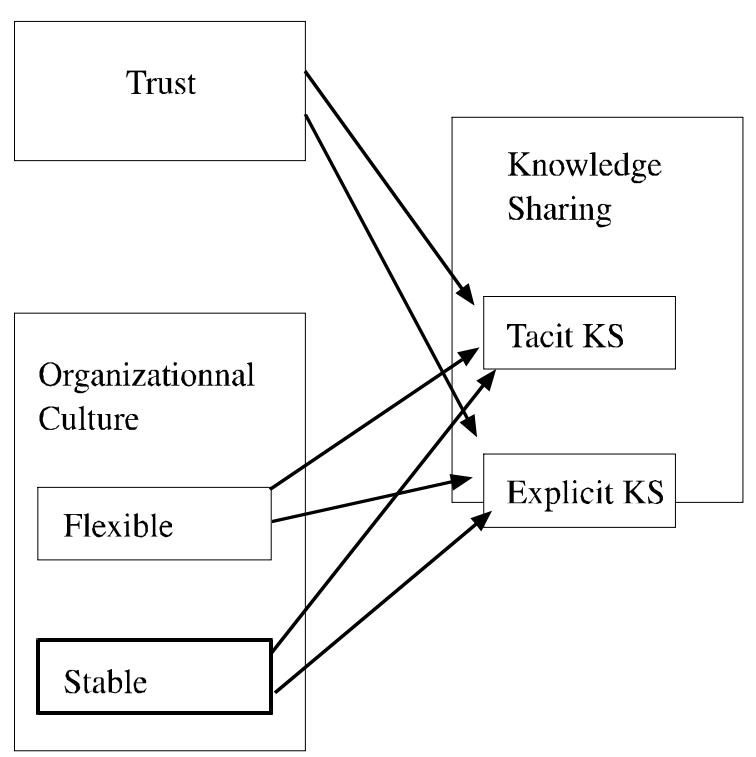

Figure 1. The theoretical model

\section{ANALYSIS}

Since the scales were used with a new sample, 19 items were submitted to exploratory analysis. A principal component analyses and scree plot indicated that four factors should be retained (eigenvalues above1.0). The best fit of data was obtained with a principal factor analysis with varimax rotation.

The results of factor analyze shows that the variables are gathered in five factors. Factor 1 consists of four trust items with an internal consistency reliability coefficient (Cronbach`s Alpha) of 0,91. Factor 2 includes four flexible culture items with an internal 
consistency reliability coefficient of 0,85 . Factor 3 includes four stable culture items with an internal consistency reliability coefficient of 0,90 . Factor 4 consists of explicit knowledge sharing items with an internal consistency reliability coefficient of 0,91 .
Lastly factor 5 includes three tacit knowledge sharing items with an internal consistency reliability coefficient of 0,90 . Table 1 shows the factor loading of trust, flexible, stable cultures, explicit and tacit knowledge sharing.

\section{Table 1. Factor analyses}

\begin{tabular}{|c|c|c|c|c|c|}
\hline Trust & 1 & 2 & 3 & 4 & 5 \\
\hline $\begin{array}{l}\text { We can rely on our partner to abide } \\
\text { by the alliance agreement }\end{array}$ &, 899 & & & & \\
\hline $\begin{array}{l}\text { There is a high level of trust in the working } \\
\text { relationship with our partner }\end{array}$ & ,933 & & & & \\
\hline $\begin{array}{l}\text { We trust that our partner's decisions will be } \\
\text { beneficial to the alliance }\end{array}$ &, 846 & & & & \\
\hline $\begin{array}{l}\text { We trust that our partner's decisions will be } \\
\text { beneficial to our firm }\end{array}$ &, 889 & & & & \\
\hline \multicolumn{6}{|l|}{ Flexible culture } \\
\hline $\begin{array}{l}\text { Most members of this organization have input } \\
\text { into decisions that affect them. }\end{array}$ & & ,792 & & & \\
\hline $\begin{array}{l}\text { Cooperation and collaboration across } \\
\text { functional roles is actively encouraged } \\
\text { within this organization. }\end{array}$ & &, 872 & & & \\
\hline $\begin{array}{l}\text { Customers' comments and recommendations } \\
\text { often lead to changes in this organization. }\end{array}$ & & 820 & & & \\
\hline $\begin{array}{l}\text { This organization is very responsive to the } \\
\text { external environment and adapts easily. }\end{array}$ & &, 860 & & & \\
\hline \multicolumn{6}{|l|}{ Stable culture } \\
\hline $\begin{array}{l}\text { In this organization there is a high level of } \\
\text { agreement about the way in which we do things. }\end{array}$ & & & ,878 & & \\
\hline $\begin{array}{l}\text { Our approach to doing business in this } \\
\text { organization is very consistent and predictable. }\end{array}$ & & & ,901 & & \\
\hline $\begin{array}{l}\text { This organization has a long-term purpose } \\
\text { and a clear direction for the future. }\end{array}$ & & & 879 & & \\
\hline $\begin{array}{l}\text { Members of this organization have a shared } \\
\text { vision as to what this organization will be } \\
\text { like in the future. }\end{array}$ & & & ,853 & & \\
\hline \multicolumn{6}{|l|}{ Explicit Knowledge Sharing } \\
\hline $\begin{array}{l}\text { We and our service provider share business } \\
\text { proposals and reports with each other }\end{array}$ & & & & ,891 & \\
\hline $\begin{array}{l}\text { We and our service provider share business } \\
\text { manuals, models, and methodologies } \\
\text { with each other. }\end{array}$ & & & &, 896 & \\
\hline $\begin{array}{l}\text { We and our service provider share each } \\
\text { other's success and failure stories }\end{array}$ & & & & ,901 & \\
\hline $\begin{array}{l}\text { We and our service provider share business } \\
\text { knowledge obtained from newspapers, } \\
\text { magazines, journals and television. }\end{array}$ & & & & 869 & \\
\hline \multicolumn{6}{|l|}{ Tacit Knowledge Sharing } \\
\hline $\begin{array}{l}\text { We and our service provider share } \\
\text { know-how from work experience with each other }\end{array}$ & & & & & ,922 \\
\hline $\begin{array}{l}\text { We and our service provider share } \\
\text { each other's know-where and know-whom }\end{array}$ & & & & & ,893 \\
\hline $\begin{array}{l}\text { We and our service provider share } \\
\text { expertise obtained from education and training }\end{array}$ & & & & & ,926 \\
\hline
\end{tabular}


Table 2

Means, standard deviations and correlations

\begin{tabular}{|l|c|c|c|c|c|c|c|}
\hline & Mean & $\begin{array}{l}\text { Standard } \\
\text { deviation }\end{array}$ & 1. & 2. & 3. & 4. & 5. \\
\hline 1.Trust & 5,7594 & 1,0996 & $(0,9143)$ & & & & \\
\hline 2. Flexible Culture & 4,8417 & 1,1720 & $0,376^{* *}$ & $(0,8557)$ & & & \\
\hline 3. Stable Culture & 5,4274 & 1,2289 & $0,215^{*}$ & $0,700^{* *}$ & $(0,8999)$ & & \\
\hline $\begin{array}{l}\text { 4. Explicit } \\
\text { Knowledge Sharing }\end{array}$ & 5,2314 & 1,3959 & $0,391^{* *}$ & $0,478^{* *}$ & $0,341^{* *}$ & $(0,9119)$ & \\
\hline $\begin{array}{l}\text { 5. Tacit Knowledge } \\
\text { Sharing }\end{array}$ & 4,9524 & 1,4828 & $0,485^{* *}$ & $0,413^{* *}$ & $0,280^{* *}$ & $0,712^{* *}$ & $(0,8965)$ \\
\hline
\end{tabular}

$* *: \mathrm{q}<0,01$

$*: \mathrm{q}<0,05$

Means, standard deviations and inter-correlations are summarized in Table 2. Cronbach`s Alpha values are shown using parentheses on the cross of the table. On a bivariate level trust, stable culture and flexible culture were positively related to explicit and tacit knowledge sharing. According to the correlation results there is a direct and positive relationship between all of the variables involved in the model.

\section{Table 3. Regression results of Research Model}

\begin{tabular}{|l|r|r|}
\hline Independent Variable & $\hat{\mathrm{a}}$ & $\mathrm{Sig}$ \\
\hline Trust &, $246^{*}$ &, 012 \\
\hline Flexible culture &, $362^{* *}$ &, 007 \\
\hline Stable culture &, 029 &, 817 \\
\hline $\begin{array}{l}\text { Dependent variable: } \\
\text { Explicit knowledge sharing }\end{array} \mathrm{R}^{2}=0.254$ & $\mathrm{~F}=11,871$ \\
\hline
\end{tabular}

$* *: \mathrm{q}<0,01, *: \mathrm{q}<0,05$

In regression analyze we investigated the influences of trust, flexible culture and stable culture together on explicit knowledge sharing. The regression model is significant as a whole $(\mathrm{F}=11,871$ : $\mathrm{p}<0,01)$; it explains $\% 25,4$ of the change of explicit knowledge sharing. This study provides empirical evidence that trust and flexible culture are related with explicit knowledge sharing. The findings shows that as we predicted in $\mathrm{H} 1$ trust (the belief in, and willingness to depend on, another party) and as we predicted in $\mathrm{H} 3$ flexible culture (an organizational culture with openness and incentive themes effectively and facilitates the integration of individual competencies into organizational knowledge base) both have positive and significant effects on explicit knowledge sharing. So our hypothesis H1 and H3 are fully supported. However the results provide no empirical evidence regarding the relationship between stable culture and explicit knowledge sharing. This means that stable culture (risk-avoiders; preferring stability and the status-quo than the uncertainty and ambiguity of change) is not related with explicit knowledge sharing. Accordingly $\mathrm{H} 5$ is not supported.

\section{Table 4. Regression results of Research Model}

\begin{tabular}{|l|r|r|}
\hline Independent Variable & $\hat{\mathrm{a}}$ & $\mathrm{Sig}$ \\
\hline Tru &, $386^{*}$ &, 000 \\
\hline Flexible culture &, $251^{* *}$ &, 045 \\
\hline Stable culture &, 021 &, 865 \\
\hline $\begin{array}{l}\text { Dependent variable: } \\
\text { Explicit knowledge sharing }\end{array}$ & $\mathrm{R}^{2}=0.254$ & $\mathrm{~F}=12,993$ \\
\hline
\end{tabular}

$* *: \mathrm{q}<0,01, *: \mathrm{q}<0,05$

In regression analyze we investigated the influences of trust, flexible culture and stable culture together on tacit knowledge sharing. The regression model is significant as a whole $(\mathrm{F}=12,993$ : $\mathrm{p}<0,01)$; it explains $\% 27,3$ of the change of tacit knowledge sharing. The results demonstrate that trust and flexible culture are related with tacit knowledge sharing. As we predicted in $\mathrm{H} 2$ trust (the belief in, and willingness to depend on, another party) and as we predicted in H4 flexible culture (an organizational culture with openness and incentive themes effectively and facilitates the integration of individual competencies into organizational knowledge base) both have positive and significant effects on explicit knowledge sharing. Accordingly our hypothesis $\mathrm{H} 2$ and $\mathrm{H} 4$ are fully supported. However the results show that there is no meaningful relationship between stable culture and explicit knowledge sharing. This means that stable culture (risk-avoiders; preferring stability and the status-quo than the uncertainty and ambiguity of change) is not related with explicit knowledge sharing. So H6 is not supported.

\section{CONCLUSION}

In this study, the relationships between trust, flexible 
culture, stable culture, explicit knowledge sharing and tacit knowledge sharing are tested in SMEs of a developing country, Turkey. The findings of the study demonstrated that trust, flexible versus stable culture, explicit and tacit knowledge sharing scales which are developed in Western countries, are appropriate for an emerging economy and eastern country; Turkey. Measures demonstrated high validity and reliability, and model results were similar with the empirical studies completed in developed and western countries.

The findings show that trust and flexible culture are positively related to tacit and explicit oriented knowledge sharing activities. This means that in today's complex, competitive and dynamic business environment which emphasizes knowledge sharing of vital importance, eagerness to give useful knowledge to others and a culture with openness and incentive themes effectively facilitate the sharing activities of both tacit and explicit knowledge within the organization.

The findings also revealed that the influence of flexible culture $(\hat{a}=0,362, p<0.01)$ is higher than trust $(\hat{a}=0,246$, $\mathrm{p}<0.05$ ) on explicit knowledge sharing; while the influence of trust ( $\hat{a}=0,386, p<0.01)$ is higher than the flexible culture $(\hat{a}=0,251, p<0.05)$ on explicit knowledge sharing. This means that an open culture with high levels of adaptability and involvement is more important for sharing articulable and codifiable knowledge which reflects system-bound side of knowledge assets of an organization than the eagerness of sharing this knowledge. However the eagerness plays a much more dominant role on sharing of tacit knowledge which is hard to document, transfer, codify, articulate, replicate and imitate than e flexible organizational culture. This may be caused by the subjective nature of the tacit knowledge.

In addition to these, the results show that there is no significant relationship between the flexible culture and tacit and explicit knowledge sharing. This means that an organizational culture preferring stability and the status-quo than the uncertainty and ambiguity of change have no use for any kind of knowledge sharing. Accordingly firms with a stable culture must immediately do something to change for their survival in today's global and competitive business environment in which knowledge is considered as a main strategic asset and sharing of this asset is of vital importance.

The findings of this study can not be taken as definite evidence because several limitations to the study results deserve commentary. First, this study is conducted on small and medium sized firms. Second, these results reported here emerge from a local area; results may differ for SMEs located on different areas that are operating in different cultural, environmental and political conditions. Third, there was not an industrial separation while evaluating data; results may differ for different industries. Despite these limitations, this study provides important implications from theoretical and practical perspectives. This study indicates that trust and flexible culture are important for knowledge sharing activities both tacit and explicit. It also demonstrates that a stable culture which emphasizes status-quo and avoids the uncertainty and ambiguity of change, is an obstacle to pass over for organizations.

In conclusion, our results indicate a significant relationship between trust, a flexible culture and knowledge sharing activities. Our findings also reveal that trust is more important for tacit knowledge sharing while a flexible culture is more important for the explicit knowledge sharing. 


\section{REFERENCES}

Argote L., Ingram P., Levine J.M. and Moreland R.L., (2000), "Knowledge transfer in organizations", Organisational Behavior and Human Decision Processes 82 (1), pp. 1-8.

Beijerse, Roelof P., (1999), “Questions in Knowledge Management: Defining and Conceptualizing a Phenomenon", Journal of Knowledge Management, $3 / 2,100$

Bhatt G. D., (2001), "Knowledge Management in Organizations: Examining the Interaction between Technologies", Techniques, and People, Journal of Knowledge Management 5(1), 68-75

Chacko E., (2003), "Culture And Therapy: Complementary Strategies For The Treatment Of Type-2 Diabetes In An Urban Setting In Kerala, India", Social Science \& Medicine, 56(5),1087-1098

Choi B. and Lee H., (2003), An Empirical Investigation of KM Styles and Their Effect on Corporate Performance, Information\&Management, 403-417

Chowdhury S., (2005), "The role of affect- and cognitions-based trust in complex knowledge sharing", Journal of Managerial Issues 17 (3), pp. 310-326.

Dirks K.T. and Ferrin, D.L. (2001), "The role of trust in organizational settings", Organization Science 12, pp. $450-467$

Du R., Ai S.and Ren Y., (2007), "Relationship between knowledge sharing and performance: A survey in Xi'an, China”, Expert Systems with Applications, Volume 32, Issue 1, Pages 38-46

G. Jones and J. George, (1998), "The experience and evolution of trust: implications for cooperation and teamwork", Academy of Management Review, 23 pp. 531-546.

GuptaB., Iyer L.S. and Aronson J.E., (2000), “A study of knowledge management practices using grounded theory approach", Journal of Scientific and Industrial Research 59 (4), pp. 668-672

Keskin, H., and Akgün A. E. and Günsel, A, and İmamog̃lu, S. Z., "The Relationships Between Adhocracy and Clan Cultures and Tacit Oriented KM Strategy", Journal of Transnational Management,
Volume 10, Issue 3, 2005.

Krogh G. von, (2002), "The communal resource and information systems", Journal of Strategic Information Systems 11 (2), pp. 85-107.

Lee J., (2001), “The impact of knowledge sharing, organizational capability and partnership quality on IS outsourcing success", Information \& Management 38 323-335

Lucas, L.M., (2005), "The impact of trust and reputation on the sharing of best practices", Journal of Knowledge Management 9 (4), pp. 87-101.

Matzler K., Rier M., Hinterhuber H.H., Renzl B. and Stadler C., (2005), "Methods and concepts in management: significance, satisfaction and suggestions for further research: perspectives from Germany, Austria and Switzerland", Strategic Change 14 (1), pp. 1-13.

Mayer R.C. and Gavin, M.B., (2005), "Trust in management and performance: who minds the shop while the employees watch the boss?", Academy of Management Journal 48 (5), pp. 874-888.

Mayer, R.C. Davis J.H. and Schoormann F.D., (1995), "An integrative model of organisational trust", Academy of Management Review 20 pp. 709-734

Mooradian T, Renzl B, Matzler K., (2007), "Who trusts? Personality, trust, and knowledge sharing", Management Learning;38, in pres

Nonaka I. and Takeuchi, H., (1995), The knowledgecreating company - how Japanese companies create the dynamics of innovation, Oxford University Press, New York/Oxford.

Nonaka, I. and Takeuchi, H., (1995), The KnowledgeCreating Company, Oxford University Press, 58

Panteli N.and Sockalingam S., (2005), "Trust and conflict within virtual inter-organizational alliances: a framework for facilitating knowledge sharing", Decision Support Systems, Volume 39, Issue 4, Pages 599-617

Perez J. R. and Pablos P. O., (2003), "Knowledge Management and Organizational Competitiveness: A Framework For Human Capital Analysis", Journal Of Knowledge Management 7 (3), 82-91, 
Polanyi, M., (1966), The Tacit Dimension. New York: Doubleday and Company Inc.

Renzl B., (2006), "Trust in management and knowledge sharing: The mediating effects of fear and knowledge documentation", Omega, In Press,

Ruppel C.P. and Harrington S.J., (2001), "Sharing knowledge through intranets-a study of organizational culture and intranet implementation", IEEE

Transactions on Professional Communication 44 (1), pp. 37-52.

Smith K.G., Collins C.J. and Clark K.D., (2005), "Existing knowledge, knowledge creation capability, and the rate of new product introduction in hightechnology firms", Academy of Management Journal 48 (2), pp. 346-357.

Wasko M.M. and Faraj, S., (2005), "Why should I share? Examining social capital and knowledge contribution in electronic networks of practice", MIS Quarterly 29 (1), pp. 35-57

Yang J., (2007), "Knowledge sharing: Investigating appropriate leadership roles and collaborative culture", Tourism Management, Volume 28, Issue 2, Pages 530543 